\title{
Protective effect of Cordia boissieri A. DC. (Boraginaceae) on metabolic syndrome
}

\author{
Asmaa I. Owis ${ }^{1 *}$, Amira M. Abo-youssef ${ }^{2}$, Ahmed H. Osman ${ }^{3}$ \\ ${ }^{1}$ Department of Pharmacognosy, Faculty of Pharmacy, Beni-Suef University, Beni-Suef, Egypt. ${ }^{2}$ Department. of Pharmacology, Faculty of Pharmacy, Beni- \\ Suef University, Beni-Suef, Egypt. ${ }^{3}$ Department of Oncology, Faculty of Veterinary Medicine, Cairo University, Cairo, Egypt.
}

\begin{tabular}{l} 
ARTICLE INFO \\
\hline Article history: \\
Received on: 01/02/2016 \\
Revised on: 06/03/2016 \\
Accepted on: $22 / 04 / 2016$ \\
Available online: $30 / 08 / 2016$
\end{tabular}

Key words:

Cordia boissieri;

Boraginaceae; metabolic

syndrome; ethyl aetate.

\begin{abstract}
Increased fructose ingestion has been linked to obesity, hyperglycemia, dyslipidemia, and hypertension associated with metabolic syndrome. Cordia boissieri A. DC. (Boraginaceae) is a slow growing beautiful plant, used traditionally as herbal remedy by diabetic Hispanic women in the Southwestern USA. The present study aimed to elucidate the toxicity and the possible protective effect of ethyl acetate extract of $C$. boissieri leaves on metabolic syndrome. Three groups of rats were fed on fructose-enriched diet for 14 weeks. One group served as fructose-enriched diet control, while the remaining groups were treated with metformin $(10 \mathrm{mg} / \mathrm{kg} / \mathrm{day})$ and ethyl acetate extract $(200 \mathrm{mg} / \mathrm{kg} /$ day $)$ during the last 4 weeks. A fourth group was fed on normal laboratory diet. At the end of the experiment, blood samples were withdrawn for the estimation of metabolic syndrome-related markers and liver samples were subjected to histopathological and immunohistochemical examination. Induction of metabolic syndrome using fructose enriched diet was associated with increased weight gain coupled with elevated levels of blood glucose, insulin, uric acid, urea, creatinine, total cholesterol, triglycerides, malondialdehyde (MDA), nitric oxide and tumor necrosis factor in addition to, decreased level of glutathione (GSH). Four-weeks oral administration of ethyl acetate extract attenuated most of the changes associated with metabolic syndrome as marked by improved insulin sensitivity, glucose tolerance, kidney function, lipid profiles and reduced oxidative stress and inflammation. The present study provides evidence of the potential protective effect of $C$. boissieri against metabolic syndrome.
\end{abstract}

\section{INTRODUCTION}

Metabolic syndrome (MS) is a disease condition characterized by variable coexistence of obesity, hyperuricemia, hyperinsulinemia, hypertension, and dyslipidemia. The pathogenesis of metabolic syndrome includes multiple organs in the cardiorenal system (Kumamoto et al., 2013). Increased consumption of fructose, commonly used in processed food and soft drinks, is one of the most important factors contributing to the growing prevalence of metabolic syndrome (Kumamoto et al., 2013). A high-fructose diet induces a well-characterized metabolic syndrome, generally resulting in hyperinsulinemia,

* Corresponding Author

Asmaa Owis, Dept. of Pharmacognosy, Faculty of Pharmacy, Beni-Suef

University, Beni-Suef, Egypt.Email: asmaa_owis@yahoomail.com hypertension, dyslipidemia, and a low HDL level. Moreover, exposure of the liver to high levels of fructose leads to rapid stimulation of lipogenesis and triglyceride accumulation, which lead to reduced insulin sensitivity and hepatic insulin resistance/glucose intolerance (Basciano et al., 2005). Natural plants as a valuable source of secondary metabolites may lower the risk of serious health disorders. Cordia boissieri A. DC. (Boraginaceae) commonly named as Texas Olive or Ancahuita, is a slow growing beautiful plant used as herbal remedy by diabetic Hispanic women in the Southwestern USA (Barwick et al., 2004; Johnson et al., 2006) and as emollient roots in the Antilles and Mexico (Hirschhorn, 1981). Jellies made from the fruits are reportedly safe to eat. Syrup made from the fruits is used to dye cloth and treat coughs. The leaves are used to alleviate rheumatism and pulmonary illness (Janick and Paull, 2008). 
Methanol-based extract from the leaves of $C$. boissieri showed significant antimicrobial activity against drug-resistant strain of Staphylococcus aureus (Molina-Salinas et al., 2007). Regarding the investigation of secondary metabolites in $C$. boissieri, so far only few phytochemical investigations have been reported. Dimethyl-3, 4'-kaempferol and p-hydroxybenzaldehyde were isolated from the fruits (Dominguez et al., 1973a, b). Moreover, forty-two volatile compounds $(97.7 \%)$ were identified in the essential oil of the flowers mainly (-)-spathulenol (19.1\%) and (E)caryophyllene $(16.2 \%)$ (Owis, 2014). To the best of the authors' knowledge, no reports concerning the safety specifications and the use of $C$. boissieri extract in treatment of MS although there is a number of studies reported for other Cordia species (Siqueira et al., 2006; Mishra and Garg, 2011; Andrade-Cetto and Heinrich, 2005; Sarathchandiran and Gnanavel, 2013). The present study aimed to assess the possible protective effect of ethyl acetate extract of $C$. boissieri leaves against metabolic syndrome induced experimentally in rats.

\section{MATERIALS AND METHODS}

\section{Animals}

All the experimental procedures were conducted using male Wistar Albino rats $(215-217 \mathrm{~g})$ provided by National Cancer Institute, Cairo, Egypt and left to accommodate in the animal facility of Faculty of Pharmacy, Beni-Suef University, for one week before being subjected to experimentation. All animals were maintained under 12-h light-dark cycle, with controlled humidity $(60-80 \%)$ and constant temperature $\left(22 \pm 1^{\circ} \mathrm{C}\right)$. Throughout the study food and water were supplied ad libitum. The study was carried out according to the guidelines of the Ethics Committee, Faculty of Pharmacy, Beni-Suef University, which followed the recommendations of the National Institutes of Health Guide for Care and Use of Laboratory Animals (Care et al., 1985).

\section{Drugs, chemicals and apparatus}

Metformin, fructose, mineral and vitamin mixtures were purchased from Sigma -Aldrich, USA. All other chemicals were of the highest grade commercially available. The concentrations of the drugs were adjusted so that each $100 \mathrm{~g}$ animal's body received orally $0.5 \mathrm{~mL}$ of either suspension containing the required dose. Glucose diagnostic kits were purchased from Biolabo SA, France. ELISA insulin kit was obtained from Biovendor, Czech Republic. Murine TNF- $\alpha$ ELISA kit was obtained from RayBiotec Co., USA. Cholesterol and triglycerides kits were purchased from Spinreact, Spain. Uric acid, urea and creatinine diagnostic kits were obtained from Biodiagnostics, Egypt.

\section{Plant material and extract preparation}

C. boissieri leaves were collected from the region of Alexandrian Road, Egypt on March 2013 and kindly authenticated by Prof. Dr. Abd Al Haleem A. Mohamed (Plant Taxonomy and Flora Research Department, Ministry of Agriculture, Giza, Egypt) for whom the authors are thankful. Voucher specimen was deposited at the Department of Pharmacognosy, Faculty of Pharmacy, Beni-Suef University, Beni-Suef, Egypt under the code: BupD-24. The plant material was air-dried and ground into powder. The air-dried powdered leaves $(2.5 \mathrm{~kg})$ were exhaustively extracted by cold maceration with methanol/ $\mathrm{H}_{2} \mathrm{O}(5 \times 5$ L) till exhaustion. The hydroalcoholic extract was evaporated under reduced pressure to give $110.2 \mathrm{~g}$ blackish semi-solid residue. The residue was suspended in distilled water and successively partitioned between $n$-hexane, chloroform and ethyl acetate. Ethyl acetate was completely evaporated under reduced pressure to afford $6.7 \mathrm{~g}$ ethyl acetate extract.

\section{Toxicity study}

Before starting animal studies, twenty five male Wistar Albino rats were used to evaluate the toxicity of ethyl acetate extract. The animals were divided into five groups of five rats each. The first group served as control group, while other groups received increasing doses of the extract, up to $2000 \mathrm{mg} / \mathrm{kg}$. All the treatments were administered by oral gavage. After administration, the animals were observed closely for $2 \mathrm{~h}$, and then at $30 \mathrm{~min}$ intervals for $6 \mathrm{~h}$ for any visible sign of toxicity. Furthermore, animals were continuously observed for 14 days for mortality and general behavior.

\section{Experimental design}

After acclimatization period of one week, rats were randomly allocated into 4 groups ( $\mathrm{n}=8$ rats per group). Group I served as negative control group (NC). This group received regular diet and water ad libitum and didn't receive any medication. Groups 2-4 were fed on FED for 15 weeks. The $2^{\text {nd }}$ group served as positive control group (FED-control), and the remaining two groups received metformin (MET $10 \mathrm{mg} / \mathrm{kg} /$ day) and ethyl acetate extract of $C$. boissieri (ECB, $200 \mathrm{mg} / \mathrm{kg} / \mathrm{day}$ ), respectively. Treatments started 10 weeks after the beginning of fructose feeding and continued for another 4 weeks. Blood samples were collected randomly after $4,6,8$ and 10 weeks from the initiation of the FED. Serum levels of fasting blood glucose (FBG), triglycerides (TG) and total cholesterol were estimated to ensure the induction of metabolic syndrome. Body weight was recorded once weekly. By the end of the treatment period, animals were fasted for $12 \mathrm{~h}$ and blood samples were withdrawn from the retroorbital plexus under light ether anesthesia for the estimation of FBG, insulin, total cholesterol, TG, uric acid, urea, creatinine, glutathione (GSH), malondialdehyde (MDA), nitric oxide (NOx) and tumor necrosis factor-alpha (TNF- $\alpha$ ) levels. Liver samples, from each group were preserved in $10 \%$ formalin prepared in saline and kept for histopathological and immunohistochemical examination.

\section{Induction of metabolic syndrome}

Metabolic syndrome was induced by feeding rats with FED according to the method described by Bezerra and coworkers (Bezerra et al., 2001). FED was composed of fructose $(660 \mathrm{~g} / \mathrm{kg})$, soya protein $(200 \mathrm{~g} / \mathrm{kg})$, sheep fat $(60 \mathrm{~g} / \mathrm{kg})$, cellulose $(30 \mathrm{~g} / \mathrm{kg}), \mathrm{L}$ - 
lysine (10 g/kg), choline chloride (10 g/kg), DL-methionine (10 $\mathrm{g} / \mathrm{kg})$, mineral mixture $(10 \mathrm{~g} / \mathrm{kg})$ and vitamin mixture $(10 \mathrm{~g} / \mathrm{kg})$. Diet was freshly prepared every $3-4$ days and stored at $2-8{ }^{\circ} \mathrm{C}$.

\section{Assessment of metabolic and biochemical parameters}

Fasting serum glucose, total cholesterol, triglycerides, uric acid, urea and creatinine levels (each as $\mathrm{mg} / \mathrm{dL}$ ) and TNF- $\alpha$ level $(\mathrm{pg} / \mathrm{mL})$ were determined using test reagent diagnostic kits as described by manufacturer's instructions. Determination of serum insulin $(\mu \mathrm{IU} / \mathrm{mL})$ was performed using rat insulin ELISA kit. Serum malondialdehyde, serum nitric oxide and blood glutathione were determined according to the methods described previously (Beutler et al., 1963, Uchiyama and Mihara, 1978, Miranda et al., 2001).

\section{Inducible nitric oxide synthase (iNOS) immunohistochemical analysis}

At the end of the experiment period, animals were decapitated. Liver tissue was removed, cleaned and fixed in $10 \%$ neutral buffered formalin overnight and transferred to $70 \%$ ethanol. Tissues were then embedded in paraffin. Paraffinembedded tissue blocks were sectioned at $4 \mu \mathrm{m}$ paraffin and were mounted on poly-L-lysine slides. Sections were air-dried, deparaffinized and rehydrated. Mounted specimens were washed in $0.01 \mathrm{~mol} / \mathrm{L}$ phosphate-buffered saline (PBS). After three washes with $\mathrm{PBS}$, an antigen retrieval solution $(0.01 \mathrm{M}$ citrate buffer, $\mathrm{pH}$ 6.0) was given for $10 \mathrm{~min}$ at $100^{\circ} \mathrm{C}$ in a microwave oven, endogenous peroxidase was eliminated by incubation in $3 \%$ $\mathrm{H}_{2} \mathrm{O}_{2}$ in $\mathrm{pH} 7.4$ in phosphate-buffered saline (PBS; $0.01 \mathrm{M}$ ) for 10 min. After washing, the specimens were treated with a blocking serum (Labvision, TR-060-UB) at room temperature for $10 \mathrm{~min}$. The sections were incubated with primary rabbit polyclonal antiinducible nitric oxide synthase (iNOS, dilution 1:100, Santa Cruz Biotechnology, Santa Cruz, CA) at room temperature for $1 \mathrm{~h}$. Then, the sections were washed 3 times with PBS and incubated with the biotinylated secondary antibody (DAKO, UK) and then streptavidin peroxidase (DAKO, UK) was given at room temperature for $30 \mathrm{~min}$. Diaminobenzidine (DAB, Sigma Chemical Company) was used as a chromogen, and the sections were counterstained with hematoxylin and were prepared for microscopic examination. Brown cytoplasmic and/or nucleolus staining in cells were considered positive (Jiang et al., 2009).

\section{Histopathological examinations}

Liver tissue specimens were fixed in $10 \%$ neutral buffered formalin. The fixed specimens were trimmed, washed and dehydrated in ascending grades of alcohol, cleared in xylene, embedded in paraffin, sectioned at 4-6 $\mu \mathrm{m}$ thickness and stained by haematoxylen and eosin (H\&E) according to (Hopwood et al., 1996). Sections were evaluated for the degree of steatosis (scale of 0-3), lobular inflammation (scale of 0-3), and hepatocellular ballooning (scale of 0-2) as described by Kleiner et al., 2005.

\section{Statistical analysis}

Data were expressed as mean values \pm S.E.M. Comparison between the mean values of different groups was carried out by using one way analysis of variance (ANOVA), followed by Tukey-Kramer post hoc test for multiple comparisons. The $\mathrm{P}$ values smaller than 0.05 were selected to indicate statistical significance between groups.

\section{RESULTS}

\section{Toxicity study}

After 14 days of observations, no visible signs of toxicity or any other abnormal behavior were observed in the test animals even, at the dose of $2000 \mathrm{mg} / \mathrm{kg}$ of body weight. Accordingly, a dose of $200 \mathrm{mg} / \mathrm{kg}$ body weight from ECB was chosen for further biological studies.

\section{Effects of metformin and ethyl acetate extract on body weight gain, serum glucose and insulin levels}

As shown in table (1), feeding rats with FED caused a significant increase in final body weight when compared to normal control group. Treatment of insulin resistant rats with MET or ECB significantly reduced final body weight as compared to FED control group. Significant increase in fasting blood glucose and serum insulin level was observed in rats fed with fructose diet $(\mathrm{p}<$ 0.05) indicating hyperinsulinemia. MET and ECB significantly reduced the rise in fasting blood glucose and serum insulin level when compared FED control group.

Table 1: Effects of metformin and ethyl acetate extract on body weight gain, serum glucose and insulin levels.

\begin{tabular}{|c|c|c|c|c|}
\hline \multirow{2}{*}{ Parameters } & \multirow{2}{*}{ Normal control $(n=8)$} & \multicolumn{3}{|c|}{ Fructose- Fed $(n=8)$} \\
\hline & & Control & MET & ECB \\
\hline Initial body weight (g) & $215.29 \pm 1.07$ & $216.90 \pm 0.61$ & $216.60 \pm 0.80$ & $215.90 \pm 0.72$ \\
\hline Final body weight (g) & $330.38 \pm 1.94$ & $365.94 \pm 2.06^{*}$ & $336.32 \pm 4.62^{@}$ & $342.30 \pm 4.41^{@}$ \\
\hline Glucose (mg/dl) & $66.90 \pm 2.07$ & $167.60 \pm 4.61 *$ & $77.92 \pm 3.34^{@}$ & $76.93 \pm 3.80^{@}$ \\
\hline Insulin $(\mu \mathrm{IU} / \mathrm{mI})$ & $11.41 \pm 0.42$ & $32.94 \pm 0.40^{*}$ & $12.08 \pm 0.32^{@}$ & $14.42 \pm 0.40^{* @}$ \\
\hline
\end{tabular}

Data was expressed as mean \pm s.e.m.; Statistical analysis was carried out using one way analysis of variance (ANOVA) followed by Tukey-Kramer multiple comparisons test. *: Significantly different from the normal control group at $\mathrm{P}<0.05$. @ : Significantly different from the fructose - control group at $\mathrm{P}<0.05$. 
Table 2: Effects of metformin and ethyl acetate extract on kidney function, lipid profile, oxidative stress biomarkers TNF $\alpha$ and NOx.

\begin{tabular}{|c|c|c|c|c|}
\hline \multirow{2}{*}{ Parameters } & \multirow{2}{*}{ Normal control $(n=8)$} & \multicolumn{3}{|c|}{ Fructose- Fed $(n=8)$} \\
\hline & & Control & MET & ECB \\
\hline Uric acid (mg/dl) & $2.60 \pm 0.34$ & $8.50 \pm 0.28^{*}$ & $3.34 \pm 0.27^{@}$ & $3.54 \pm 0.40^{\varrho}$ \\
\hline Urea $(\mathrm{mg} / \mathrm{dl})$ & $30.28 \pm 1.51$ & $57.97 \pm 1.56^{*}$ & $34.70 \pm 2.15^{@}$ & $43.70 \pm 2.30^{* \Subset}$ \\
\hline Creatinine $(\mathrm{mg} / \mathrm{dl})$ & $0.42 \pm 0.03$ & $0.90 \pm 0.04^{*}$ & $0.44 \pm 0.04^{@}$ & $0.50 \pm 0.03^{\circledR}$ \\
\hline Triglycerides (mg/dl) & $47.90 \pm 1.73$ & $82.30 \pm 1.62^{*}$ & $53.80 \pm 1.83^{@}$ & $49.02 \pm 2.80^{\complement}$ \\
\hline Total cholesterol $(\mathrm{mg} / \mathrm{dl})$ & $51.83 \pm 1.92$ & $93.26 \pm 1.80^{*}$ & $52.73 \pm 1.92^{@}$ & $58.21 \pm 2.71^{@}$ \\
\hline $\operatorname{MDA}(\mathrm{nmol} / \mathrm{ml})$ & $2.60 \pm 0.34$ & $8.50 \pm 0.28^{*}$ & $3.34 \pm 0.27^{@}$ & $4.38 \pm 0.34^{@}$ \\
\hline GSH (mg\%) & $78.84 \pm 1.70$ & $36.13 \pm 3.24^{*}$ & $73.14 \pm 2.60^{@}$ & $72.20 \pm 2.70^{\complement}$ \\
\hline $\mathrm{TNF} \alpha(\mathrm{pg} / \mathrm{ml})$ & $37.43 \pm 1.70$ & $149.10 \pm 4.25^{*}$ & $45.06 \pm 2.43^{@}$ & $39.80 \pm 1.80^{\complement}$ \\
\hline $\mathrm{NOx}(\mu \mathrm{mol} / \mathrm{ml})$ & $43.70 \pm 2.30$ & $86.90 \pm 3.14^{*}$ & $46.13 \pm 2.22^{@}$ & $49.80 \pm 1.72^{@}$ \\
\hline
\end{tabular}

Data was expressed as mean \pm s.e.m.; Statistical analysis was carried out using one way analysis of variance (ANOVA) followed by Tukey-Kramer multiple comparisons test. *: Significantly different from the normal control group at $\mathrm{P}<0.05$. @ : Significantly different from the fructose - control group at $\mathrm{P}<0.05$.

Table 3: Histological scoring and grading system.

\begin{tabular}{cccc}
\hline \multirow{2}{*}{ Group } & & \multicolumn{1}{c}{ Scoring } & Hepatocyte ballooning (0-2) \\
\cline { 2 - 4 } & Steatosis (0-3) & Lobular inflammation (0-3) & 0 \\
NC & 0 & 2 & 2 \\
MC & 3 & 0 & 1 \\
MET & 0 & 0 & 2 \\
ECB & 0 & & 2 \\
\hline
\end{tabular}

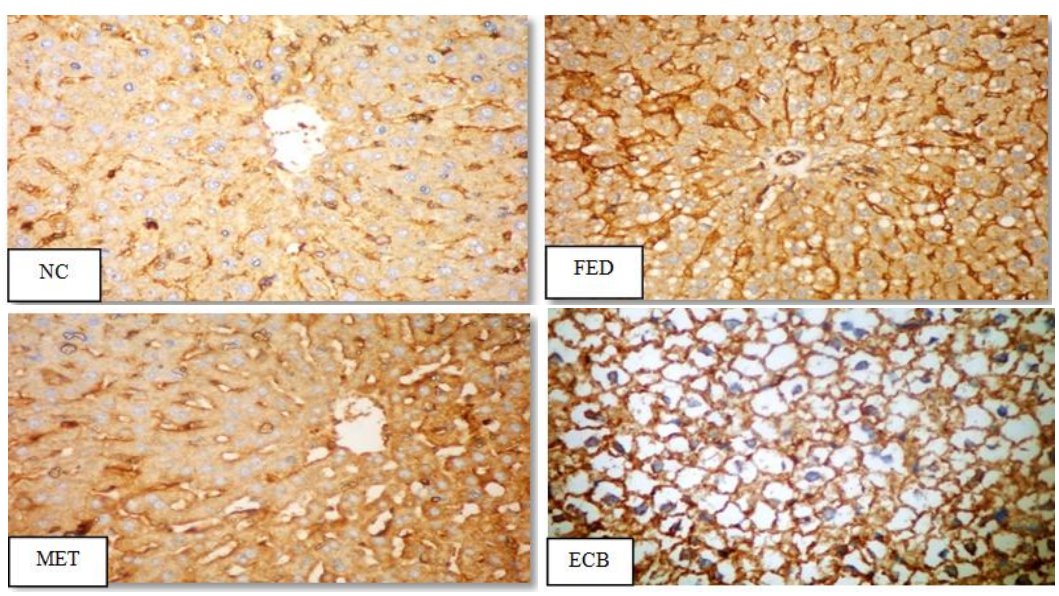

Fig.1: NC group: showing no detectable stain in cytoplasm and nuclei of control group. FED group: showing uniform distribution of stain in the hepatocytes. MET group: showing no detectable stain in cytoplasm and nuclei. ECB group: Showing cell ballooning with non-detectable stain. (X 200)

\section{Effects of metformin and ethyl acetate extract on kidney function and lipid profile}

As compared with normal control rats, fructose fed rats exhibited clustering features of MS including elevated levels of uric acid, urea and creatinine. Treatment of rats with MET or ECB reversed the elevated serum levels of uric acid, urea and creatinine as compared with FED control group.

Levels of serum total cholesterol and triglycerides were significantly elevated in MS rats compared to those of the control group ( $\mathrm{p}<0.05)$. MET as well as ECB significantly alleviated dyslipedemia by decreasing total serum cholesterol and triglycerides levels in MS rats as shown in Table 2.

\section{Effects of metformin and ethyl acetate extract on oxidative stress biomarkers, TNF- $\alpha$ level and nitric oxide (NOx) level}

As shown in table 2, MS showed significant increase in serum MDA level and significant decrease in blood GSH level as compared to normal control group. Oral administration of MET and ECB showed statistically significant reduction in serum MDA level and significant increase in blood GSH level in relation with FED control group. TNF- $\alpha$ and NOx levels in non-treated FED rats raised to $149.10 \pm 4.25$ and $86.90 \pm 3.14$ respectively when compared to normal control group. Treatment of FED rats with MET and ECB reduced both TNF- $\alpha$ and NOx levels when compared to FED control group.

\section{Immunohistochemical (iNOS) findings}

Normal control group showed no detectable stain granules in cytoplasm and nuclei. The brown granules were noticed in the endothelial lining of hepatic sinusoids and portal blood vessels. FED group revealed uniform distribution of stain in the hepatocytes in both cytoplasm and nuclei of degenerated cells. Treatment of rats with MET showed relatively no detectable stain in cytoplasm and nuclei. Group treated with ECB revealed cell ballooning with non detectable stain (Figure 1). 

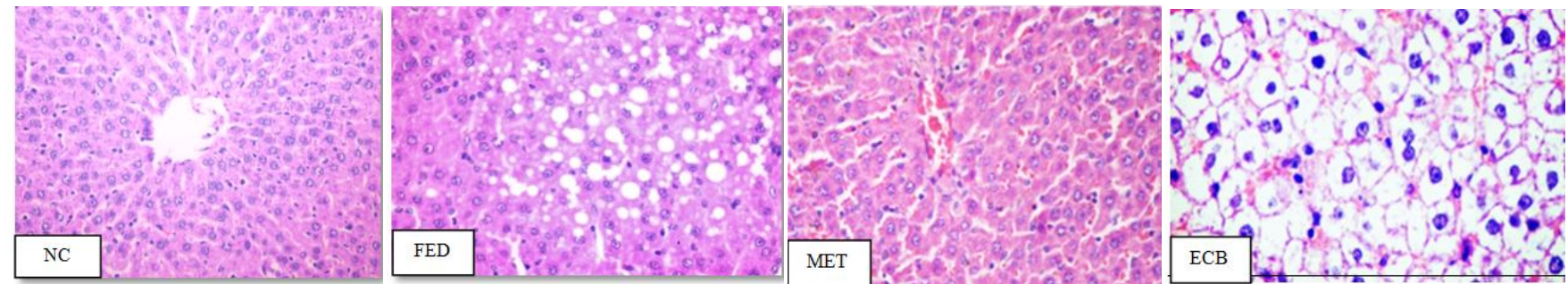

Fig. 2: NC group: showing normal histological structure score (0). FED group: showing sever steatosis score (3). MET group: showing complete abscent of steatosis score (0). ECB group: showing ballooning of hepatocytes score (2). (X 200)

\section{Histopathological examination:}

As illustrated in table (3) and figure (2): normal control group (NC) showed normal histological structure of hepatic lobules and organization of hepatic cords. Steatosis, lobular inflammation and ballooning of hepatocytes were displayed score (0). The experimental group (FED control) revealed disorganization of hepatic cord. Massive steatosis of hepatocytes score (3), lobular inflammation and ballooning score (2) were also seen.

All treated groups were examined in comparison with normal and FED control groups. Group treated with MET appeared resembling to control group in steatosis and lobular inflammation grade (0) but hepatocytes ballooning revealed score (1). Group treated with ECB revealed only ballooning of hepatocytes score (2).

\section{DISCUSSION}

\section{Cordia boissieri and metabolic syndrome}

The present investigation aimed at elucidating the possible protective effects as well as the possible underlying mechanisms of ethyl acetate extract of $C$. boissieri leaves against fructose-induced metabolic syndrome in rats and confirming the results by histopathological and immunohistochemical studies. Maintaining rats on FED for 14 weeks was associated with increased weight, hyperglycemia, hyperinsulinemia, dyslipedemia, disrupted renal function, inflammation and oxidative stress. These results come in consistent with previous studies which demonstrated that rats fed with high carbohydrate and high fat diet for few months developed MS as revealed by insulin resistance, dyslipidemia, vascular dysfunction and inflammation (Nascimento et al., 2013). The reported increase in weight in FED rats could be attributed to an increase in adiposity (Elliott et al., 2002), hyperinsulinemia and hyperglycemia. The increased blood glucose together with increased serum insulin level clearly suggests that insulin action on glucose regulation was impaired (Aragno et al., 2009). ECB showed a significant reduction in body weight in FED rats. This could be attributed partially to the correction hyperglycemia and hyperinsulinemia (Lustig et al., 2004) in addition to, decreased lipid absorption and lipogenesis due to the synergistic action of flavonoid mixture present in the extract. The beneficial effect of ECB is mainly attributed to the presence of flavonoids in it and could be explained by one of the following mechanisms: reduction of glucose absorption through inhibition of $\alpha$-glucosidase activity (Kim et al., 2000), increased adenosine monophosphate-activated protein kinase (AMPK) activity and glucose transporter 4 (GLUT4) expression in skeletal muscle cells. The present investigation demonstrated that MS in rats was associated with an elevation in serum uric acid, urea and creatinine levels. This reflects an impairment in glomerular filtration rate (GFR) and kidney dysfunction. The increased serum uric acid in MS rats might be due to increase its hepatic production (Jalal $e t$ al., 2013, Marriott et al., 2009) and /or reduction in GFR (Feig et al., 2008, Suliman et al., 2006). Moreover accumulating evidences suggest that hyperinsulinemia enhanced urate reabsorption and reduced urate excretion in the kidney (Galvan et al., 1995). ECB significantly ameliorated glomerular filtration rate and kidney function as shown by reduced serum uric acid urea and creatinine levels. ECB possibly modulates the expression of renal specific transporters and enhancement of renal excretion of urate in FED rats (Hu et al., 2009).

The present findings are in harmony with those of other investigators (Busserolles et al., 2003, Hininger-Favier et al., 2009, Thresher et al., 2000) as it showed that FED rats exhibited dyslipedemia as marked by increased TG and total cholesterol. This could be attributed to over production of lipids in liver and decrease of its clearance (Mayes, 1993) through the decrease in lipoprotein activity in endothelial cells (Nakagawa et al., 2006). Another possible explanation is that most of ingested fructose is converted to fatty acids as it is bypass key regulatory step in glycolysis. Fatty acids are then esterified into TG which are packed into lipoprotein with cholesterol for blood transport (Calejman et al., 2012). Moreover, ECB corrected dyslipidemia induced in MS rats. The mechanism of ECB effect on lipid profile could be attributed to the presence of flavonoids in the extract which have been reported to decrease lipid absorption at the gastrointestinal level by inhibiting the activity of pancreatic lipase (Kawaguchi et al., 1997). Flavonoids can also modulate the activity of different enzymes involved in lipid metabolism and the expression of transcription factors involved in TG and cholesterol synthesis for example, sterol regulatory element-binding proteins SREBP-1, and SREBP-2 (Horton et al., 2002).

In the current study, a significant increase in MDA level and significant reduction in GSH level was observed in FED rats. These results are consistent with other findings that showed that oxidative stress may be important characteristics of diet-induced MS in animal models (Chung et al., 2013). ECB succeeded in complete correction of oxidative stress. The antioxidant effect of 
ECB could be mainly attributed to the presence of flavonoids which are known to anchor on the polar head of the main phospholipids. Hence, distributed on the surface of the lipid bilayers as well as the aqueous phase and could scavenge free radicals as a result of its hydrogen donating ability (Ishisaka et al., 2011).

The high level of circulating TNF- $\alpha$ was primarily considered to be an inflammatory response, which is known to be causally related to MS (Bradley, 2008). The elevation of circulating TNF- $\alpha$ was demonstrated concomitantly with upregulation of pro-inflammatory iNOS protein expression (Kröncke et al., 1998). In the current study, ECB attenuated the increment in TNF- $\alpha$ level. Flavonoids are known to interfere with inflammatory signaling, inflammatory cytokines (Fraga and Oteiza, 2011) and reduce TNF- $\alpha$ secretion (Rivera et al., 2008). Another possible explanation is possibly related to decreased levels of uric acid. As reported before, hyperuricemia has shown to mediate pro-inflammatory response in the adipose tissue and has been associated with inflammation. Uric acid induced up regulation of monocyte chemoattractive protein expression, increased macrophage infiltration and pro-inflammatory responses in adipose tissue (Baldwin et al., 2011).

The increase in NOx production after FED administration could be a secondary event following the increase in iNOS (Son and Hall, 2000). Our study showed similar correlation in which the increase in NOx production was accompanied with increase in iNOS expression. These findings suggest that NOx production contributes to the pathogenesis of MS as increased production of NO has been shown to be induced by inflammation (Kröncke et al., 1998). Furthermore, NO inhibits the ability of cells to repair damaged DNA by inhibiting DNA repair proteins (Wink et al., 1997). In this study, we have provided evidence that ECB, totally reduced NOx activity. This is in good accordance with the immunohistochemistry studies which reported the attenuation of iNOS expression. ECB possibly reduced the amount of pro-inflammatory cytokines in MS rats, and hence, NOx production. It is well known that flavonoids and flavonoidcontaining foods interfere with inflammatory signaling (Fraga and Oteiza, 2011) and the expression of the proinflammatory iNOS (Rivera et al., 2008).

\section{CONCLUSIONS}

The present investigation demonstrated that ethyl acetate extract of $C$. boissieri leaves possesses a potent protective effect against metabolic and biochemical changes associated with fructose-induced metabolic syndrome and could be used as a safe remedy for treatment of diabetes. It improved insulin sensitivity, glucose tolerance, kidney function, lipid profiles and reduced oxidative stress and inflammation possibly due to its flavonoid content. This study provides scientific evidence of the health benefits of $C$. boissieri consumption for the first time.

Conflicts of Interest: The authors declare no conflicts of interest.

\section{ACKNOWLEDGEMENT}

The authors wish to thank Scientific Research Development Unit, Beni-Suef University, Beni-Suef, Egypt for financial support.

\section{REFERENCES}

Andrade-Cetto A, Heinrich M. Mexican plants with hypoglycaemic effect used in the treatment of diabetes. J Ethnopharmacol, 2005; 99:325-348.

Aragno M, Tomasinelli CE, Vercellinatto I, Catalano MG, Collino M, Fantozzi R, Danni O, Boccuzzi G. SREBP-1c in nonalcoholic fatty liver disease induced by Western-type high-fat diet plus fructose in rats. Free Radic Biol Med, 2009; 47:1067-1074.

Baldwin W, Mcrae S, Marek G, Wymer D, Pannu V, Baylis C, Johnson RJ, Sautin YY. Hyperuricemia as a mediator of the proinflammatory endocrine imbalance in the adipose tissue in a murine model of the metabolic syndrome. Diabetes, 2011; 60: 1258-1269.

Barwick M, Van Der Schans A, Claudy JB. 2004. Tropical \& Subtropical Trees: A Worldwide Encyclopaedic Guide.United Kingdom: Thames Hudson Ltd.

Basciano H, Federico L, Adeli K. Fructose, insulin resistance, and metabolic dyslipidemia. Nutr metab, 2005; 2: 5-19.

Beutler E, Duron O, Kelly BM. Improved method for the determination of blood glutathione. J Lab Clin Med, 1963; 61:882-888.

Bezerra R, Ueno M, Silva M, Tavares D, Carvalho C, Saad M, Gontijo, J.A high-fructose diet induces insulin resistance but not blood pressure changes in normotensive rats. Braz J Med Biol Res, 2001; 34: 1155-1160.

Bradley J. TNF-mediated inflammatory disease. J Pathol, 2008; 214: $149-160$

Busserolles J, Gueux E, Rock E, Demigné C, Mazur A, Rayssiguier, Y. Oligofructose protects against the hypertriglyceridemic and pro-oxidative effects of a high fructose diet in rats. J Nutr, 2003; 133: 1903-1908.

Calejman CM, Di Gruccio JM, Mercau ME, Repetto EM, Astort F, Sanchez R, Pandolfi M, Berg G, Schreier L, Arias P. Insulin sensitization with a peroxisome proliferator-activated receptor $\gamma$ agonist prevents adrenocortical lipid infiltration and secretory changes induced by a high-sucrose diet. J Endocrinol, 2012; 214: 267-276.

Care IoLARCo, Animals UoL, Resources NIoHDoR. 1985. Guide For The Care and Use of Laboratory Animals. Washington DC, USA: National Academies.

Chung SW, Kang SG, Rho JS, Kim HN, Song IS, Lee YA, Heo SJ, Song SW.The Association between Oxidative Stress and Metabolic Syndrome in Adults.Korean J Fam Med, 2013; 34: 420-428.

Dominguez X, Escarria S, Butruille D. Dimethyl-3, 4'kaempferol de Cordia boissieri. Phytochemistry, 1973a; 12: 724-725.

Dominguez X, Escarria S, Butruille D. $\rho$-Hydroxybenzaldehyde dans le fruit de Cordia boisieri. Phytochemistry, 1973b; 12: 2996.

Elliott SS, Keim NL, Stern JS, Teff K, Havel PJ. Fructose, weight gain, and the insulin resistance syndrome. Am J Clin Nutr, 2002; 76: 911-922.

Feig DI, Soletsky B, Johnson RJ. Effect of allopurinol on blood pressure of adolescents with newly diagnosed essential hypertension: a randomized trial. JAMA, 2008; 300: 924-932.

Fraga CG, Oteiza PI. Dietary flavonoids: role of $(-)$-epicatechin and related procyanidins in cell signaling. Free Radic Biol Med, 2011; 51: 813-823.

Galvan AQ, Natali A, Baldi S, Frascerra S, Sanna G, Ciociaro D, Ferrannini E.Effect of insulin on uric acid excretion in humans. Am $J$ Physiol Endocrinol Metab, 1995; 268: E1-E5.

Hininger-Favier I, Benaraba R, Coves S, Anderson RA, Roussel AM.Green tea extract decreases oxidative stress and improves insulin sensitivity in an animal model of insulin resistance, the fructose-fed rat. $J$ Am Coll Nutr, 2009; 28: 355-361. 
Hirschhorn HH. Botanical remedies of South and Central America, and the Caribbean: an archival analysis. Part I. $J$ Ethnopharmacol, 1981; 4: 129-158.

Hopwood D, Bancroft J, Stevens A. 1996. Theory and Practice of Histological Techniques.Edinburgh, London, Melbourne, New York: Churchill Livingstone.

Horton JD, Goldstein JL, Brown MS. SREBPs: activators of the complete program of cholesterol and fatty acid synthesis in the liver. $J$ Clin Invest, 2002; 109: 1125-1132.

Hu QH, Wang C, Li JM, Zhang DM, Kong LD.Allopurinol, rutin, and quercetin attenuate hyperuricemia and renal dysfunction in rats induced by fructose intake: renal organic ion transporter involvement. $A m$ J Physiol Renal Physiol, 2009; 297: F1080-F1091.

Ishisaka A, Ichikawa S, Sakakibara H, Piskula MK, Nakamura T, Kato Y, Ito M, Miyamoto KI, Tsuji A, Kawai Y. Accumulation of orally administered quercetin in brain tissue and its antioxidative effects in rats. Free Radic Biol Med, 2011; 51: 1329-1336.

Jalal DI, Chonchol M, Chen W, Targher G.Uric acid as a target of therapy in CKD. Am J Kidney Dis, 2013; 61: 134-146.

Janick J, Paull RE. 2008. The Encyclopedia of Fruit and Nuts. London, UK: CABI.

Jiang WW, Kong LB, Li GQ, Wang XH. Expression of iNOS in early injury in a rat model of small-for-size liver transplantation. Hepatobiliary Pancreat Dis Int, 2009; 8:146-151.

Johnson L, Strich H, Taylor A, Timmermann B, Malone D, Teufel-Shone N, Drummond R, Woosley R, Pereira E, Martinez A.Use of herbal remedies by diabetic Hispanic women in the southwestern United States. Phytother Res, 2006; 20: 250-255.

Kawaguchi K, Mizuno T, Aida K, Uchino K. Hesperidin as an inhibitor of lipases from porcine pancreas and Pseudomonas. Biosci Biotechnol Biochem, 1997; 61: 102-104.

Kim JS, Kwon CS, Son KH. Inhibition of alpha-glucosidase and amylase by luteolin, a flavonoid. Biosci Biotechnol Biochem, 2000; 64: 2458-2461.

Kleiner DE, Brunt EM, Van Natta M, Behling C, Contos MJ, Cummings OW, Ferrell LD, Liu YC, Torbenson MS, Unalp-Arida A. Design and validation of a histological scoring system for nonalcoholic fatty liver disease. Hepatology, 2005; 41: 1313-1321.

Kröncke K, Fehsel K, Kolb-Bachofen V. Inducible nitric oxide synthase in human diseases. Clin Exp Immunol, 1998; 113: 147-156.

Kumamoto R, Uto H, Oda K, Ibusuki R, Tanoue S, Arima S, Mawatari S, Kumagai K, Numata M, Tamai T. Dietary fructose enhances the incidence of precancerous hepatocytes induced by administration of diethylnitrosamine in rat. Eur J Med Res, 2013; 18: 54-62.

Lustig R, Sen S, Soberman J, Velasquez-Mieyer P.Obesity, leptin resistance, and the effects of insulin reduction. Int J Obes, 2004; 28:1344-1348.

Marriott BP, Cole N, Lee E. National estimates of dietary fructose intake increased from 1977 to 2004 in the United States. J Nutr, 2009; 139:1228S-1235S.

Mayes PA. Intermediary metabolism of fructose. Am J Clin Nutr, 1993; 58: 754S-765S.

Miranda KM, Espey MG, Wink DA. A rapid, simple spectrophotometric method for simultaneous detection of nitrate and nitrite. Nitric oxide, 2001; 5: 62-71.
Mishra A, Garg GP. Antidiabetic activity of fruit pulp of Cordia dichotoma in alloxan induced diabetic rats. Int J Pharm Sci Res, 2011; 2: 2314-2319.

Molina-Salinas G, Pérez-López A, Becerril-Montes P, SalazarAranda R, Said-Fernández S, De Torres NW.Evaluation of the flora of Northern Mexico for in vitro antimicrobial and antituberculosis activity. $J$ Ethnopharmacol, 2007; 109: 435-441.

Nakagawa $\mathrm{T}$, Hu H, Zharikov S, Tuttle KR, Short RA, Glushakova O, Ouyang X, Feig DI, BlockER, Herrera-Acosta J. A causal role for uric acid in fructose-induced metabolic syndrome. Am J Physiol Renal Physiol, 2006; 290: F625-F631.

Nascimento AR, Machado M, Jesus N, Gomes F, Lessa MA, Bonomo IT, Tibiriçá E. Structural and functional microvascular alterations in a rat model of metabolic syndrome induced by a high-fat diet. Obesity, 2013; 21:2046-2054.

Owis AI. Composition of essential oil from flowers of Cordia boissieri A. DC. and revision on the use of sesquiterpenes as taxonomic markers for genus Cordia.WJPPS, 2014; 3: 133-141.

Rivera L, Morón R, Sánchez M, Zarzuelo A, Galisteo M.Quercetin ameliorates metabolic syndrome and improves the inflammatory status in obese Zucker rats. Obesity, 2008; 16: 2081-2087.

Sarathchandiran I, Gnanavel M. Anti-diabetic activity of the isolated compounds of Cordia sebestena in high fat diet fedstreptozotocin-induced diabetic rats.IJBPR, 2013; 4: 1050-1056.

Siqueira VLD, Cortez DAG, Oliveira CED, Nakamura CV, Bazotte RB. Pharmacological studies of Cordia salicifolia Cham in normal and diabetic rats. Braz Arch Biol Technol, 2006; 49: 215-218.

Son KK, Hall KJ. Nitric oxide-mediated tumor cell killing of cisplatin-based interferon-gamma gene therapy in murine ovarian carcinoma. Cancer Gene Ther, 2000; 7: 1324-1328.

Suliman ME, Johnson RJ, García-López E, Qureshi AR, Molinaei H, Carrero JJ, Heimbürger O, Bárány P, Axelsson J, Lindholm B.J-shaped mortality relationship for uric acid in CKD. Am J Kidney Dis, 2006; 48: 761-771.

Thresher JS, Podolin DA, Wei Y, Mazzeo RS, Pagliassotti MJ.Comparison of the effects of sucrose and fructose on insulin action and glucose tolerance. Am J Physiol Regul Integr Comp Physiol, 2000; 279: R1334-R1340.

Uchiyama M, Mihara M. Determination of malonaldehyde precursor in tissues by thiobarbituric acid test. Anal Biochem, 1978; 86: 271-278.

Wink DA, Cook JA, Christodoulou D, Krishna MC, Pacelli R, Kim S, Degraff W, Gamson J, Vodovotz Y, Russo A. Nitric oxide and some nitric oxide donor compounds enhance the cytotoxicity of cisplatin. Nitric Oxide, 1997; 1:88-94.

\section{How to cite this article:}

Owis A, Abo-youssef A. Protective effect of Cordia boissieri A. DC. (Boraginaceae) on metabolic syndrome. J App Pharm Sci, 2016; 6 (08): 083-089. 